\title{
Simulated analysis of summer climate on centennial time scale in eastern China during the last millennium
}

\author{
WANG HongLi ${ }^{1,2}$, LIU Jian $^{1 *}$, WANG ZhiYuan ${ }^{1,2}$, WANG SuMin ${ }^{1} \&$ KUANG XueYuan ${ }^{3}$ \\ ${ }^{1}$ State Key Laboratory of Lake Science and Environment, Nanjing Institute of Geography and Limnology, Chinese Academy of Sciences, Nanjing \\ 210008, China; \\ ${ }^{2}$ Graduate University of Chinese Academy of Sciences, Beijing 100049, China; \\ ${ }^{3}$ School of Atmospheric Sciences, Nanjing University, Nanjing 210093, China
}

Received January 20, 2011; accepted April 27, 2011

\begin{abstract}
Using Lanczos filtered simulation results from the ECHO-G coupled ocean-atmosphere model, this study analyzes the spatiotemporal structure of temperature and precipitation on centennial time scale to examine how climate change in eastern China responded to external forcing during the last millennium. The conclusions are (1) eastern China experienced a warm-cold-warm climate transition, and the transition from the warm period to the cold period was slower than the cold to warm transition which followed it. There was more rainfall in the warm periods, and the transitional peak and valley of precipitation lag those of temperature. The effective solar radiation and solar irradiance have significant impacts on the temporal variation of both temperature and precipitation. Volcanic activity plays an important role in the sudden drop of temperature before the Present Warm Period (PWP). There is a positive correlation between precipitation and volcanic activity before 1400 A.D., and a negative relationship between the two thereafter. The concentration of greenhouse gases increases in the PWP, and the temperature and precipitation increase accordingly. (2) The spatial pattern of the first leading empirical orthogonal function (EOF) mode of temperature on centennial time scale is consistent with that on the inter-annual/inter-decadal (IA-ID) time scales; namely, the entirety of eastern China is of the same sign. This pattern has good coherence with effective solar radiation and the concentrations of greenhouse gases. The first leading EOF mode of precipitation on centennial time scale is totally different from that on the IA-ID time scales. The first leading mode of centennial time scale changes consistently over the entirety of eastern China, while the middle and lower reaches of the Yangtze and Yellow Rivers are the opposite to the rest of eastern China is the leading spatial pattern on IA-ID time scale. The distribution of precipitation on centennial time scale is affected by solar irradiance and greenhouse gas concentrations.
\end{abstract}

last millennium, eastern China, Lanczos filtering, centennial time scale, summer climate

Citation: Wang H L, Liu J, Wang Z Y, et al. Simulated analysis of summer climate on centennial time scale in eastern China during the last millennium. Chinese Sci Bull, 2011, 56: 2229-2235, doi: 10.1007/s11434-011-4548-2

Knowledge of different paleoclimates can improve our understanding of modern and future climate variability. This key understanding is why paleoclimate will be the topic of the fifth chapter in the upcoming IPCC Fifth Assessment Report. Studies based on geological records focus on millennial time scales, whereas those based on instrumental records focus on IA-ID time scales. The last millennium is the key period for studying climate change on centennial

*Corresponding author (email: jianliu@niglas.ac.cn) time scale, hence bridging the geological records and instrumental observations. Researchers have used proxybased reconstructions [1-3] in different areas of the world and model simulations [4] to study global, hemispherical, and regional climate variability during the last two millennia. Research into the last millennium has had an emphasis on temperature changes.

Climate change has a significant influence on sustainable development of eastern China. Studying past climate can improve our understanding of the processes and mecha- 
nisms behind the climate variability experienced, and can provide researchers with a scientific basis for better forecasting future climate change. In recent years, studies on past climate in eastern China have yielded regional proxybased temperature records [5-9], dry/wet indexes [10-12] or precipitation [13-16] time series with record lengths of 1000-2650 years at various temporal resolutions. These data are reconstructed using historical documents, stalagmites, tree rings, ice cores, and lake sediments. These reconstructions are spatially inhomogeneous at various temporal resolutions. It has been shown that temperature reconstructions of the last 500 years using Chinese proxies are of high consistency, although this is less true earlier periods [17].

There are many important results which inform our understanding of past climates that are based on proxy data or reconstructions. The spatial and temporal resolutions of these reconstructions, however, can hamper our systematic understanding of the spatiotemporal structure and underlying dynamic processes of the climate system. To some extent, simulations can compensate for the limitations of the reconstructions by providing assessments of the mechanisms of historical climatic change from dynamic view points, and provide information for regions where proxy archives are difficult to obtain. Recently, several global climate models have been developed for the study of the last millennium $[4,18-20]$, and climate variability in China during the last millennium has been simulated [21-23].

There has been work on the temperature variation in China during the last 500 years [24], and that in eastern China during the last millennium [25]. The variability of the global [26] and East Asian [27] summer monsoon precipitation, as well as the inter-hemispheric comparison of climate change [28] during the last millennium has also been studied. Here, our focus is summer climate change on centennial time scale in eastern China, including the mechanistic basis of such changes. Specifically, (1) In terms of the spatial and temporal characteristics of temperature and precipitation, is there any difference in spatial patterns between changes on centennial and IA-ID time scales? And (2) How does the temporal and spatial distribution of climate change in eastern China respond to external forcing? What are the dominant factors behind such climate change?

\section{Datasets}

Datasets include monthly temperature and precipitation and during 1000-1990 A.D. in a forced simulation using ECHO-G coupled ocean-atmosphere model [29]. The horizontal resolution of the model is T30, or approximately $3.75^{\circ} \times 3.75^{\circ}$. The external forcing factors of the model include solar irradiance, volcanism, and greenhouse gas concentrations (including $\mathrm{CO}_{2}$ and $\mathrm{CH}_{4}$ ) for the period of 1000 to 1990 A.D. obtained from the ice core data in the Antarctic [30,31]. The solar irradiance is calculated with the effects of sunspots and cosmic ray isotope included [32]. The radiation forcing effect of volcanic ash is estimated according to the concentration of sulfides in the Greenland ice core [33]. The effective solar radiation is calculated by the atmospheric model including the solar irradiance and results of volcanism.

The validation of the model performance in simulating modern and past climate variations in China indicates that the ECHO-G model successfully reflects the main temporal and spatial variations of temperature $[24,25]$ and precipitation $[27,34]$ which have occurred in China during the last millennium. We filtered time series with a Lanczos filter, which significantly reduces the effect of the Gibbs oscillation on filter function [35], for diagnostic analysis.

\section{Centennial variations of the summer climate in eastern China during the last millennium}

The study area is eastern China $\left(105^{\circ}\right.$ to $125^{\circ} \mathrm{E}, 20^{\circ}$ to $55^{\circ} \mathrm{N}$ ), which is located in the East Asian monsoon region. Due to the middle and lower reaches of the Yangtze River entering the monsoon rainy season in May, the summer precipitation is defined as the mean of May-to-August (MJJA) rainfall. For consistency, the summer temperature is also the mean of MJJA temperature.

All the series have centennial resolution. A Lanczos lowpass filter has been used to remove all the higher frequency variability (shorter than 100 years), and the series are hereinafter referred to as "the filtered series". The use of filter function results in loss of partial data at the beginning and end of the filtered series. To avoid the use of partial data, the length of the filtered series used in the present study is 931 years (1030-1960 A.D.), which discards 30 years of data at the beginning and end of the filtered series.

\subsection{Temporal evolution of temperature and precipita- tion and their responses to external forcing}

Figure 1 compares temperature and precipitation changes over eastern China with the external forcing change. The summer temperature in eastern China experienced five warm and cold periods alternately during the last millennium, indicated by solid and dashed vertical lines, respectively. The temperature evolution on centennial time scale is broadly consistent with the reconstruction in three regions of eastern China (see Figure 3 in [17]). The last millennium is divided into three stages according to temperature change:

(1) The Medial Warm Period (MWP, 1030-1250 A.D.).

The warmest epoch in the MWP covered half of the 12th century. Since it has been pointed out $[36,37]$ that winters of the 12th century had low temperatures, we examined the simulated winter temperature (not shown) as complementary information. The result indicates that 12 th century winters were some of the coldest periods in the last millennium. This implies the temperature difference between summer 


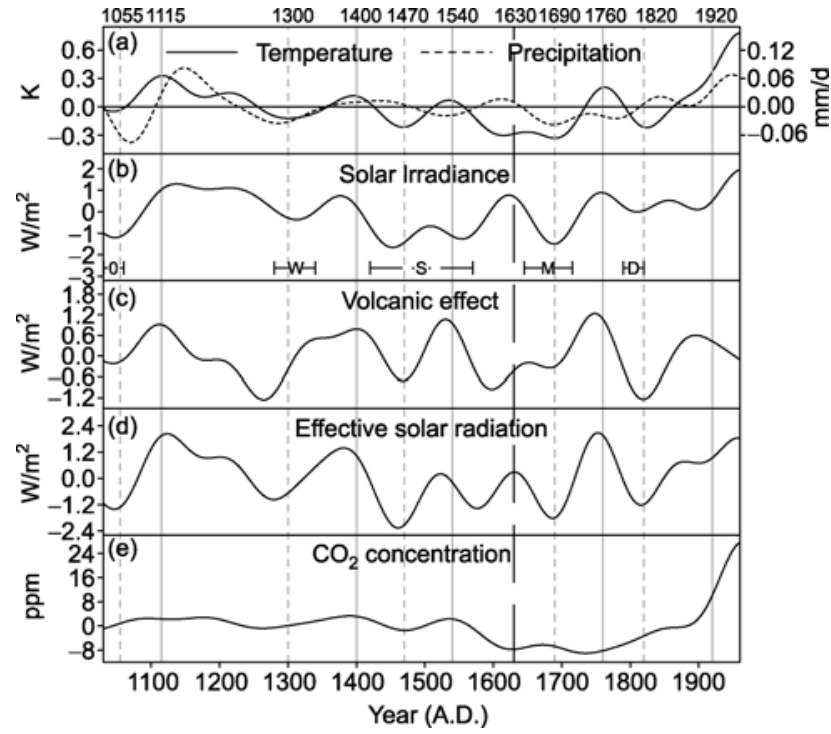

Figure 1 Centennial variability of climate and external forcing in eastern China during the last millennium. (a) Summer temperature (solid line, left coordinate) and precipitation (dotted line, right coordinate); (b) solar irradiance; (c) volcanic activity; (d) effective solar radiation; (e) $\mathrm{CO}_{2}$ concentration. The upper case letters of $\mathrm{O}, \mathrm{W}, \mathrm{S}, \mathrm{M}$, and D in (b) represent the Oort Minimum, Wolf Minimum, Spörer Minimum, Maunder Minimum, and Dalton Minimum, respectively.

and winter in 12th century eastern China was large.

(2) The Little Ice Age (LIA, 1250-1850 A.D.). Warm epochs, (when the temperature was above zero), occupied a relatively short time and cold epochs dominated in this period. It was rather cold in the 15th, 17th, and 19th centuries. The longest cold epoch was in the 17 th century, which is consistent with the cold winter temperatures.

(3) PWP (1850-1960 A.D.). The increasing trend of temperature with model results is consistent with the variation in the instrumental data on the inter-decadal time scale [38], and exceeds the maximum temperature in the MWP after 1920 A.D. Eastern China had twice experienced slight cooling and warming from the end of the MWP (1250 A.D.) to the LIA minima (1550 A.D.). The time from the end of the LIA minima (1730 A.D.) to the PWP (1850 A.D.) is about 120 years, and in this sense, the transition from a warm period to a cold period is slower than from a cold to a warm one.

To investigate how summer temperatures in eastern China responded to external forcing, we compared the temperature with filtered series of solar irradiance, volcanic activity, effective solar radiation, and $\mathrm{CO}_{2}$ concentration (Figure 1). Figure 1(a) and (b) illustrate that solar irradiance impacted on the trend of temperature change. The correlation coefficient between the two is 0.604 at the $99 \%$ confidence level (the freedom of filtered series is calculated using the method of Yan et al. [39], and similarly hereinafter). The correlation coefficient between temperature and volcanic activity is 0.497 at the $95 \%$ confidence level. The active volcanism played an important role in sudden drops of temperature prior to the PWP. Volcanism strengthened during the five low-temperature episodes. Volcanic forcing was largely responsible for the temperature drop in 1820 A.D. [40]. The effective solar radiation is the most significant forcing factor for temperature, the correlation coefficient between them is 0.749 at the $99 \%$ confidence level. The five higher (lower) temperatures mentioned earlier correlated to higher (lower) effective solar radiation. However, the trend is inconsistent with the positive correlation between temperature and effective solar radiation around 1630 A.D. (long dotted vertical line in Figure 1). The intensities of effective solar radiation around 1630 A.D. and 1530 A.D. were almost at the same level, while the temperature showed obvious differences in the two periods. The concentration of $\mathrm{CH}_{4}$ showed fewer changes and the $\mathrm{CO}_{2}$ decreased somewhat (Figure 1(e)), indicating that the cold trend around 1630 A.D. may be due to the decrease in the concentration of $\mathrm{CO}_{2}$. The effective solar radiation after 1920 A.D. was weaker than that in early 12th century, while the warming after 1920 A.D. was stronger than that in early 12th century. The warming was in accordance with the increase of the concentration of greenhouse gases after 1850 A.D. Compared with the warm period in the MWP, greenhouse gases were one of the main contributors in the PWP to the abrupt increase of temperature experienced then.

The precipitation trend almost always followed the transition between two periods of the MWP, the LIA, and the PWP (Figure 1(a)). In-phase and out-of-phase variations between temperature and precipitation both occurred in the MWP and the LIA, however, the climate change showed an in-phase relationship between temperature and precipitation at the MWP maximum, the LIA minima, and the PWP. There was higher rainfall in the warm periods and less in cold periods, with more clear fluctuation in the MWP and the PWP than in the LIA. The greatest fluctuation occurred in the MWP, since the highest (12th century) and lowest (11th century) rainfall episodes were both in this period. Both rainfall and its fluctuation decreased, and the dry period of the 16th century was the least severe among the three dry periods occurring during the LIA. There was more rainfall in the PWP than in the LIA. The rainfalls had five peak to valley changes, which lagged the temperature slightly. The lag time was about 30 years before 1250 A.D. and 70 years between 1400-1900 A.D. This may be due to the change of external forcing, first induce the variation of the temperature field, leading to the variation of the water cycle related to the phase transformation of water. In the early 15 th century, mid-17th century, and early 18 th century, rainfalls amounts appeared to increase slightly, and although the amplitudes were different from those in other studies [12], the periods in the two studies are similar.

The correlation coefficient between precipitation and solar irradiance in Figure 1 is 0.579 at the $99 \%$ confidence level. Except between 1400 and 1500 A.D. (Figure 1(a), (b)), precipitation increases or decreases with increases or 
decreases in solar irradiance. The decrease of precipitation lagged behind the weakening of solar irradiance and the strengthening of volcanic activity at the Oort Minimum. Although this time was a very dry period, that may be due to the different modulation level of solar irradiance on precipitation in different solar minima [41]. There was a positive correlation between precipitation and volcanic activity before 1400 A.D. and higher (lower) values of precipitation correlated to lower (higher) levels of volcanic activity, while the relationship between the two changed to a negative one after 1400 A.D. (Figure 1(a), (c)). Before 1400, the correlation coefficient between precipitation and effective solar radiation is 0.481 at the $95 \%$ confidence level (Figure 1(a), (d)). Thereafter, the confidence level decreased due to the change in response of precipitation to volcanic activity in 1400 A.D. Rainfall and greenhouse gases (Figure 1(a), (e)) both increased in the PWP, although the increasing trend of rainfall was more gentle than that of the greenhouse gases.

\subsection{Spatial structures of temperature and precipitation and their responses to external forcing}

We applied the EOF analysis to identify major spatial structures of summer temperature and precipitation in eastern China on centennial time scale. According to the rule given by North et al. [42], the first two leading modes are statistically distinguished from the higher mode. Therefore, we use the first two EOF modes to learn about the spatial structure of the summer climate. The spatial patterns represent the variability structures of temperature and precipitation, because the data used in the EOF analysis is normalized anomalies, so the isolines show the magnitude of the variability [43]. The first leading mode of temperature accounts for a large proportion of the total variance (85.59\%). The salient feature (Figure 2(a)) is that the entirety of eastern China is of the same sign, the centers of positive signs are located in the middle and lower reaches of the Yellow River $\left(110^{\circ}-115^{\circ} \mathrm{E}\right)$ and the northern area near $55^{\circ} \mathrm{N}$. The variability at high latitude is higher than that at low latitude, and most areas of variability in the east are bigger than those in the west. The second mode only contributes 3.38\% to the total variance. The spatial pattern (Figure 2(b)) exhibits two areas of opposite signs (negative in northeastern China and positive in the rest of eastern China), with $41^{\circ} \mathrm{N}$ as the boundary between them. A center of positive sign is located in the middle and lower reaches of the Yellow River $\left(110^{\circ}-115^{\circ} \mathrm{E}\right)$, and a center of negative sign is located in northeastern China. The first two leading EOF modes suggest that the dominant spatial characteristic of summer temperature over the entirety of eastern China varies consistently on centennial time scale, and the variation of temperature in this pattern is more sensitive in high-latitude area. An alternative spatial pattern where temperature varies oppositely between northeastern China and the rest of eastern China is rare.

The first leading mode of precipitation accounts for $19.73 \%$ of the total variance. The spatial pattern (Figure 2(c)) shows only two small regions in the sea to the south and outside of the frontier to the north which are different from the whole continent of eastern China. Thus, the precipitation changes consistently over the whole landmass of eastern China. The variability is higher in low-latitude areas. The area south of the middle and lower reaches of the Yangtze River where there is a center of positive sign has
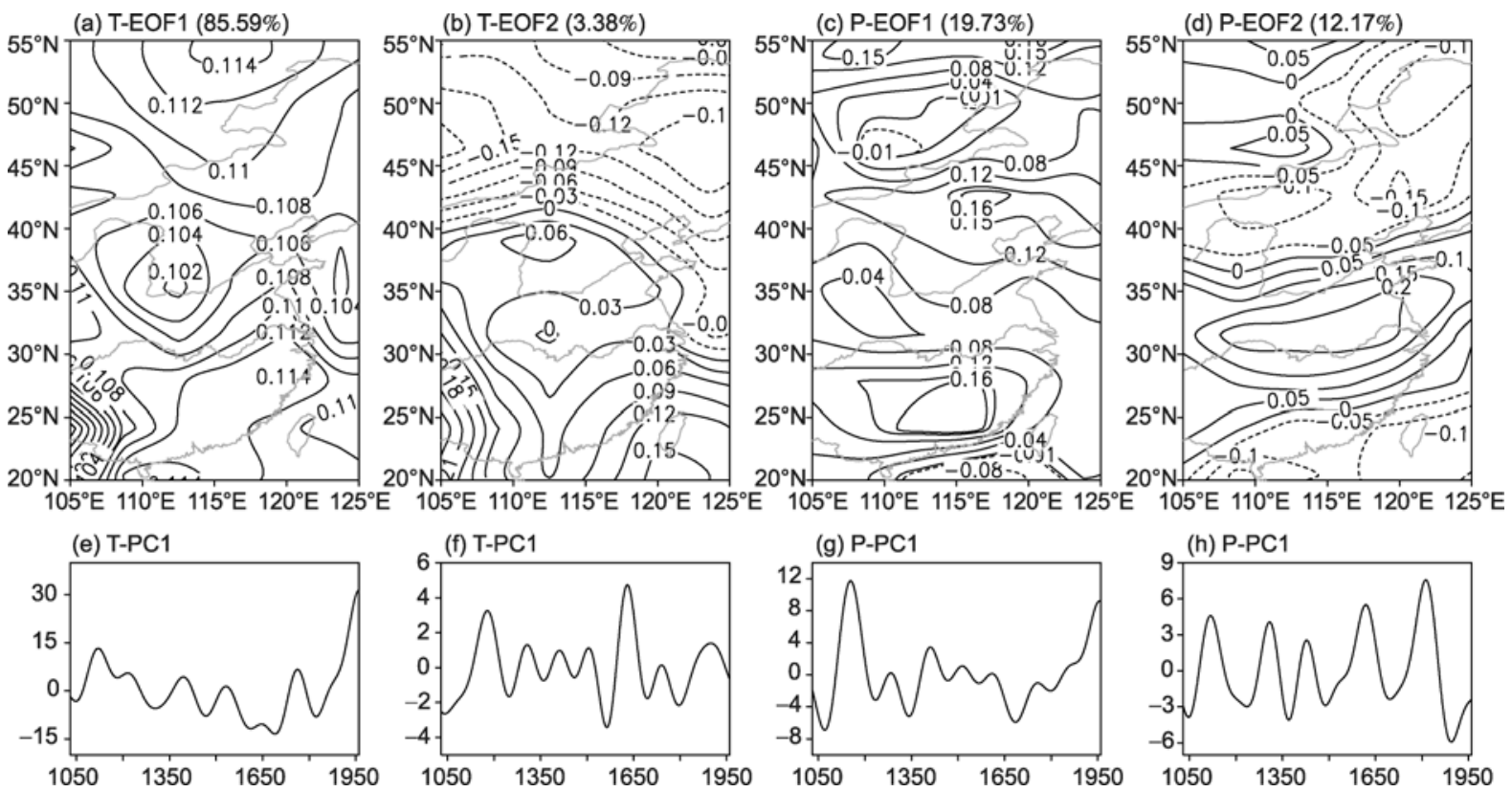

Figure 2 Spatial pattern of the first two leading EOF modes associated with the normalized MJJA temperature ((a), (b)) and precipitation ((c), (d)) anomalies in eastern China and the corresponding principle components ((PC); (e)-(h)). 
abundant summer precipitation. The second mode accounts for $12.17 \%$ of the total variance, and it reveals a pattern with "negative-positive-negative" phases from south to north (Figure 2(d)). There is no significant difference among the three subregions, the positive center locates in the middle and lower reaches of the Yangtze River. The first two leading EOF modes indicate that the dominant spatial variation of summer precipitation has approximate the same phase in eastern China, while the phase of second mode in the middle and lower reaches of the Yangtze and Yellow Rivers are opposite to the rest of the domain. The two leading spatial structures both demonstrate that precipitation variability is clearer in low-latitude areas.

The spatial structures of summer temperature and precipitation on IA-ID time scales are also analyzed using the EOF method, based on the filtered series. The results indicate that the spatial patterns of first two modes of temperature on centennial time scale are consistent with the EOF analysis of the IA-ID series, while the leading EOF spatial pattern of precipitation on centennial time scale is totally different from that on IA-ID time scales. The first leading mode of IA-ID time scales from the EOF analysis based on model or gauge results [44] shows that the middle and lower reaches of the Yangtze and Yellow Rivers are opposite to the rest of this domain, which is different from result on centennial time scale. However, the first leading mode of IA-ID time scales is similar to the second mode of centennial time scale. Liu et al. [27] showed that the variation of extra- tropical and subtropical rainfall also tends to follow the effective solar radiation forcing closely on centennial time scale, and the forced response features are in-phase rainfall variability between the extra-tropics and subtropics when they studied the latitude dependence of monsoon rains. Therefore, the difference between the spatial pattern of the first leading mode of precipitation on centennial time scale and IA-ID time scales is primarily determined by effective solar radiation.

The correlation coefficients between the PCs on centennial time scale and the external forcing (Table 1) illustrate that the first leading mode of temperature has good coherence with the effective solar radiation and greenhouse gases, and that the second mode responds to the solar irradiance quite well. Northeastern China has a negative correlation while the rest has a positive correlation with solar irradiance due to the two areas of opposite sign. The solar irradiance and greenhouse gases are positively correlated with changes in the first leading mode of precipitation, and the second mode responds to greenhouse gases quite well. The middle and lower reaches of the Yangtze and Yellow Rivers have a negative correlation while the rest of the region has a positive correlation with greenhouse gases due to spatial distribution.

\section{Discussion and conclusions}

This study analyses the spatiotemporal structures of temperature and precipitation in eastern China on centennial time scale to examine how climate change in this region responded to external forcing during the last millennium. The main conclusions are:

(1) The climate experienced warm-cold-warm transitions, and the transition from the warm period to the cold is slower than that from the cold to the warm. There were divergent trends between summer and winter temperatures in the 12th century: the summer was warmer and winter was colder. The effective solar radiation is the most significant factor affecting temperature variation; higher (lower) temperature values correlate well with higher (lower) effective solar radiation. Solar irradiance impacts the trend of temperature change. The active volcanism plays an important role in sudden drops of temperature prior to the PWP. Greenhouse gases impact the abrupt temperature increases in the PWP, and this relation should be calibrated by other model results.

(2) There is more rainfall in the two warm periods than in the cold period. The precipitation had more variable in the MWP and PWP than in the LIA. The transitions of peak and valley changes of precipitation lag those of temperature. Solar irradiance impacts precipitation significantly; strong (weak) solar irradiance corresponds to high (low) precipitation. There was a positive correlation between the precipitation and volcanic activity before 1400 A.D., thereafter, the relationship between the two changed to a negative correlation. How the volcanic impact on precipitation changed around 1400 A.D., and how greenhouse gases affect rainfall in the PWP need further study.

(3) The spatial pattern of the first leading EOF mode of temperature on centennial time scale is consistent with that on IA-ID time scales; that is, the entire domain is of the

Table 1 Correlation coefficients between the principal components and external forcing ${ }^{\text {a) }}$

\begin{tabular}{ccccc}
\hline & Factor & Solar irradiance & Volcanic activity & Effective solar radiation \\
\hline T & PC1 & $0.629^{* *}$ & $0.464^{*}$ & $0.75^{* *}$ \\
& PC2 & $0.39^{*}$ & 0.031 & $0.788^{* *}$ \\
\hline \multirow{2}{*}{$\mathrm{P}$} & PC1 & $0.525^{* *}$ & 0.16 & 0.008 \\
& PC2 & 0.072 & -0.281 & $0.497^{*}$ \\
\hline
\end{tabular}

a) $*$ indicates a $95 \%$ confidence level; $* *$ indicates a $99 \%$ confidence level. 
same sign and the variability at high latitude is higher than that at low latitude, and the variability in most areas in the east is higher than that in the west. This pattern has good coherence with effective solar radiation and greenhouse gases. The second mode varied oppositely between northeastern China and the remaining areas of eastern China, such a distribution is rare. This pattern is mainly affected by solar irradiance.

(4) The first leading EOF mode of precipitation on centennial time scale is very different from that on IA-ID time scales. The first leading mode of centennial time scale changed consistently over the whole landmass of eastern China. This distribution is affected by solar irradiance and greenhouse gases. The first leading mode of IA-ID time scales is similar to the second mode of centennial time scale, which is that the middle and lower reaches of the Yangtze and Yellow Rivers are opposite to the rest of the domain. The second mode of the centennial time scale responds to greenhouse gases quite well. The impacts of external forcing in different areas should be investigated with further studies.

The authors would like to thank Dr. Eduardo Zorita for providing the simulation datasets. The authors also thank the editor and three anonymous reviewers for their valuable comments and suggestions. This work was supported by the Strategic and Special Frontier Project of Science and Technology of the Chinese Academy of Sciences (XDA05080800), the National Basic Research Program of China (2010CB950102, 2010CB833404 and 2011CB403301), the National Natural Science Foundation of China (40871007 and 40890054), and the Knowledge Innovation Program of the Chinese Academy of Sciences (KZCX2-YW-337).

1 Jones P D, Mann M E. Climate over past millennia. Rev Geophys, 2004, 42: 1-42

2 Ljungqvist F. Temperature proxy records covering the last two millennia: A tabular and visual overview. Geogra Anna Ser A-Phys Geogr, 2009, 91: 11-29

3 Mann M E. Climate over the past two millennia. Ann Rev Earth Planet Sci, 2007, 35: 111-138

4 Min S K, Legutke S, Hense A, et al. Internal variability in a $1000-\mathrm{yr}$ control simulation with the coupled climate model ECHO-G-I. Near-surface temperature, precipitation and mean sea level pressure. Tellus, 2005, 57A: 605-621

5 Tan M, Liu T S, Hou J Z, et al. Cyclic rapid warming on centennialscale revealed by a 2650 -year stalagmite record of warm season temperature. Geophys Res Lett, 2003, 30: 1617-1620

6 Yang B, Braeuning A, Johnson K R. General characteristics of temperature variation in China during the last two millennia. Geophys Res Lett, 2002, 29: 38-31

7 Zhang $\mathrm{P}$ Z, Cheng H, Edwards R L, et al. A test of climate, sun, and culture relationships from an 1810-year Chinese cave record. Science, 2008, 322: 940-942

8 Ge Q S, Zheng J Y, Fang X Q, et al. Temperature changes of winterhalf-year in eastern China during the past 2000 years (in Chinese). Quat Sci, 2002, 22: 166-173

9 Wang S W, Wen X Y, Luo Y, et al. Reconstruction of the temperature series of China for the last 1000 years. Chinese Sci Bull, 2007 , 52: 958-964

10 Zhang D E, Liu C Z, Jiang J M. Reconstrucion of six regional dry/wet series and their abrupt changes during the last 1000 years in east China (in Chinese). Quat Sci, 1997, 1: 1-11
11 Jiang T, Zhang Q, Wang S M. The relationship between droughts, floods and climatic changes in the middle and lower reaches of the Changjiang River since last 1000 years (in Chinese). Quat Sci, 2004, 24: $518-524$

12 Zheng J Y, Wang W C, Ge Q S, et al. Precipitation variability and extreme events in eastern China during the past 1500 years. Terr Atmos Ocean Sci, 2006, 17: 579-592

13 Ge Q S, Zheng J Y, Hao Z X, et al. Reconstruction of historical climate in China: High-resolution precipitation data from Qing Dynasty archives. Bull Amer Meteorol Soc, 2005, 86: 671-679

14 Ge Q S, Guo X F, Zheng J Y, et al. Meiyu in the middle and lower reaches of the Yangtze River since 1736. Chinese Sci Bull, 2008, 53: 107-114

15 Zheng J Y, Hao Z X, Ge Q S. Seasonal precipitation reconstruction and analysis in Shandong province derived from the archives in the Qing Dynasty since 1736 (in Chinese). Clim Environ Res, 2004, 9: 551-566

16 Zheng J Y, Hao Z X, Ge Q S. Reconstruction of annual precipitation in the middle and lower reaches of the Yellow River for the last 300 years. Sci China Ser D-Earth Sci, 2005, 48: 2182-2197

17 Ge Q S, Zheng J Y, Hao Z X, et al. Temperature variation through 2000 years in China: An uncertainty analysis of reconstruction and regional difference. Geophys Res Lett, 2010, 37: L03703

18 Zhou T J, Wu B, Wen X Y, et al. A fast version of LASG/IAP climate system model and its 1000-year control integration. Adv Atmos Sci, 2008, 25: 655-672

19 Zhou T J, Man W M, Zhang J. Progress in numerical simulations of the climate over the last millennium (in Chinese). Adv Ear Sci, 2009, 24: 469-476

20 Man W M, Zhou T J, Zhang J, et al. The equilibrium response of LASG/IAP climate system model to prescribed external forcing during the little ice age (in Chinese). Chin J Atmos Sci, 2010, 34: 914-924

21 Peng Y, Xu Y, Jin L. Climate changes over eastern China during the last millennium in simulations and reconstructions. Quat Intern, 2009, 208: $11-18$

22 Shen C, Wang W C, Peng Y, et al. Variability of summer precipitation over eastern China during the last millennium. Clim Past, 2009, 5: $129-141$

23 Fan F, Mann M E, Ammann C M. Understanding changes in the Asian Summer Monsoon over the past millennium: Insights from a long-term coupled model simulation. J Clim, 2009, 22: 1736-1748

24 Liu J, Von Storch H, Zorita E, et al. Simulated and reconstructed temperature in China since 1550 AD. Hist Meteorol, 2005, 2: 87-104

25 Liu J, Von Storch H, Chen X, et al. Simulated and reconstructed winter temperature in eastern China during the last millennium. Chinese Sci Bull, 2005, 50: 2872-2877

26 Liu J, Wang B, Ding Q H, et al. Centennial variations of the global monsoon precipitation in the last millennium: Results from ECHO-G model. J Clim, 2009, 22: 2356-2371

27 Liu J, Wang B, Wang H L, et al. Forced response of the East Asian summer rainfall over the past millennium: Results from a coupled model simulation. Clim Dyn, 2011, 36: 323-336

28 Kuang X Y, Liu J, Wang H L, et al. Inter-hemispheric comparison of climate change in the last millennium based on the ECHO-G simulation. Chinese Sci Bull, 2008, 53: 2692-2700

29 Von Storch H, Zorita E, Jones J M, et al. Reconstructing past climate from noisy data. Science, 2004, 306: 679-682

30 Etheridge D, Steele L, Langenfelds R, et al. Morgan natural and anthropogenic changes in atmospheric $\mathrm{CO}_{2}$ over the last 1000 years from air in Antarctic ice and firn. J Geophys Res, 1996, 101: 4115 $-4128$

31 Blunier T, Chappellaz J, Schwander J, et al. Variations in atmospheric methane concentration during the Holocene epoch. Nature, 1995, 374: 46-49

32 Usoskin I, Solanki S, Schüssler M, et al. Millennium-scale sunspot number reconstruction: Evidence for an unusually active Sun since the 1940s. Phys Rev Lett, 2003, 91: 211101

33 Robock A, Free M. 1996. The volcanic record in ice cores for the past 2000 years. In: Jones P, Bradley R, Jouzel J, eds. Climatic Variation 
and Forcing mechanisms of the Last 2000 Years. New York: SpringerVerlag, 533-546

34 Kuang X Y, Liu J, Wang H L, et al. Comparison of simulated and reconstructed precipitation in China during the last millennium (in Chinese). Adv Ear Sci, 2009, 24: 159-171

35 Duchon C. Lanczos filtering in one and two dimensions. J Appl Meteorol, 1979, 18: 1016-1022

36 Zhu K Z. Climatic changes in the past 5000 years in China (in Chinese). Sci China, 1973, 2: 168-189

37 Ge Q S, Zheng J Y, Fang X Q, et al. Winter half-year temperature reconstruction for the middle and lower reaches of the Yellow River and Yangtze River, China, during the past 2000 years. The Holocene, 2003, 13: 933-940

38 Zhai P and Pan X. Trends in temperature extremes during 1951-1999 in China. Geophys Res Lett, 2003, 30: 1913-1916

39 Yan H M, Zhong M, Zhu Y Z. The determination of degrees of freedom for digital filtered time series-An application in the correlation analysis between length of day variation and SOI (in Chinese). Acta Astron Sin, 2003, 44: 324-329

40 Wagner $\mathrm{S}$, Zorita $\mathrm{E}$. The influence of volcanic, solar and $\mathrm{CO}_{2}$ forcing on the temperatures in the Dalton Minimum (1790-1830): A model study. Clim Dyn, 2005, 25: 205-218

41 Muscheler R, Joos F, Beer J, et al. Solar activity during the last 1000 yr inferred from radionuclide records. Quat Sci Rev, 2007, 26: 82-97

42 North G R, Bell T L, Cahalan R F, et al. Sampling errors in the estimation of empirical orthogonal functions. Mon Weather Rev, 1982, 110: 699-706

43 Wei F Y. Modern Technology of Statistics, Diagnosis and Forecast for Climate (in Chinese). Beijing: China Meteorological Press, 1999. 121

44 Zhang Q Y, Lv J M, Yang L M, et al. The interdecadal variation of precipitation pattern over China during summer and its relationship with the atmospheric internal dynamic processes and extra-forcing factors (in Chinese). Chin J Atmos Sci, 2007, 31: 1290-1300

Open Access This article is distributed under the terms of the Creative Commons Attribution License which permits any use, distribution, and reproduction in any medium, provided the original author(s) and source are credited. 